Journal of Community Based Environmental Engineering and Management, 2019, Vol. 3, No. 2: 57-64

\title{
PENGEMBANGAN PENGELOLAAN SISTEM PERSAMPAHAN AREA WISATA GRAMA TIRTA JATILUHUR MENGGUNAKAN PRINSIP CONTINGENT VALUATION METHOD
}

\author{
Rafi Khaistan Isyala ${ }^{*}$, Kancitra Pharmawati \\ Program Studi Teknik Lingkungan, Institut Teknologi Nasional Bandung
}

\begin{abstract}
Abstrak
Area Wisata Grama Tirta Jatiluhur (GTJ) merupakan suatu destinasi wisata yang hampir seluruh fasilitas yang disediakan mengandalkan keindahan alam sekitar Waduk dan menjadikannya daya tarik utama bagi setiap pengunjung, yang pada kondisinya tidak terhitung menjadi nilai ekonomi area wisata GTJ karena tidak memiliki nilai pasar. Tujuan melakukan valuasi ekonomi adalah untuk memperkecil dampak dari kegagalan pasar akibat tidak memilikinya nilai guna sehingga menjadikan peluang terjadinya eksploitasi pada lingkungan menyebabkan pencemaran lingkungan terjadi di area wisata GTJ. Pencemaran lingkungan di area wisata GTJ disebabkan oleh sampah yang dibuang tidak pada tempatnya karena kurang baiknya sistem pewadahan dan pengumpulan sampah. Pendekatan yang digunakan dalam valuasi ekonomi adalah Contingent Valuation Method (CVM) untuk menngukur nilai keberadaan dari sumber daya alam yang di eksploitasi dan menyebabkan pencemaran. Prinsip CVM yang digunakan adalah pasar hipotesa, penawaran pengembangan sistem pewadahan dan persampahan dan Willingness to Pay (WTP) pengunjung. Penggunaan prinsip tersebut memberikan solusi untuk pengembangan pengelolaan sistem persampahan khususnya sistem pewadahan dan pengumpulan sampah. WTP yang didapat dijadikan dasar biaya sistem pewadahan dan pengumpulan sampah. WTP total yang didapat adalah Rp.988.330.500 dengan WTP rata-rata pengunjung adalah Rp.4.500.
\end{abstract}

Kata kunci: Grama Tirta Jatiluhur, CVM, Sistem Persampahan, WTP

\section{Pendahuluan}

Destinasi Pariwisata adalah kawasan yang berada pada satu ataupun lebih wilayah administratif yang berisikan daya tarik wisata, fasilitas umum, fasilitas pariwisata, aksesibilitas, dan masyarakat yang saling terkait dan melengkapi terwujudnya kepariwisataan (UU Nomor 10 Tahun 2009). Obyek wisata adalah suatu bentukan dari aktifitas dan fasilitas yang berhubungan, yang dapat menarik minat

${ }^{*}$ Penulis Korespondensi:

E-mail: rafi.khaistan@gmail.com

Diterima pertama kali: 23 Agustus 2019

Direvisi : 28 Agustus 2019

Disetujui untuk publikasi: 29 Agustus 2019 wisatawan atau pengunjung untuk datang ke suatu daerah atau tempat tertentu (Marpaung, 2002).

Area wisata Grama Tirta Jatiluhur (GTJ) merupakan salah satu destinasi pariwisata yang terletak di Kecamatan Jatiluhur, Kabupaten Purwakarta. Area wisata GTJ merupakan destinasi pariwisata yang dikelola oleh Perum Jasa Tirta II (PJT II). Daya tarik yang diberikan area wisata GTJ mengandalkan keindahan dari Waduk Ir. H. Djuanda. Pepohonan yang rindang dan udara yang segar menjadi salah satu alasan wisatawan berkunjung ke area wisata GTJ. Keunggulan area wisata GTJ adalah berbagai macam jenis rekreasi yang dapat digunakan 
seperti memancing di Waduk, Waterworld, penginapan terapung, perahu, resto, penangkaran hewan seperti rusa dan monyet, dan fasilitas bermain anak. Keunggulan tersebut membuat area wisata GTJ banyak digunakan sebagai tempat berkumpul oleh organisasi maupun instansi pemerintahan.

Keunggulan area wisata GTJ tersebut tidak memiliki nilai guna yang pasti sehingga dibutuhkannya valuasi ekonomi untuk memberikan nilai kuantitatif tersebut. Tidak adanya nilai guna yang pasti menjadikan terjadinya sebuah ekternalitas dikarenakan suatu barang atau jasa yang tidak memiliki nilai guna termasuk kegagalan pasar yang menyebabkan inefisiensi dalam alokasi sumber daya (Sugiyanto \& Fikri, 2016).

Kondisi eksisting area wisata GTJ terjadi eksploitasi lingkungan yang menyebabkan pencemaran. Pencemaran yang terjadi akibat sampah yang tidak dibuang pada tempatnya, kurang baiknya sistem pewadahan dan pengumpulan. Pengunjung merasa bahwa tidak melihat adanya wadah sampah di sekitar dan ada yang melihat wadah sampah sudah dengan kondisi yang buruk.

Pendekatan valuasi ekonomi yang dipilih untuk menghitung nilai keberadaan sehingga dapat mengatasi eksploitasi pada sumber daya alam adalah Contingent Valuation Method (CVM) (Fauzi, 2004). Penggunaan prinsip dari CVM bertujuan untuk mengembangkan pengelolaan sistem persampahan khususnya sistem pewadahan dan pengumpulan sampah di area wisata GTJ dengan cara melibatkan pengunjung. Pengunjung terlibat secara tidak langsung dalam pengembangan sistem pewadahan dan pengumpulan sampah melalui Willingnes to Pay (WTP). Pengembangan pengelolaan sistem persampahan khususnya sistem pewadahan dan pengumpulan sampah dilakukan agar sesuai dengan standar dengan SNI 19-2454-2002 tentang Tata Cara Teknik Operasi Pengelolaan Sampah Perkotaan Biaya.

\section{Metodologi Penelitian}

Persiapan Penelitian

Sebelum melakukan penelitian, persiapan penelitian diperlukan untuk menjadi dasar dalam melakukan penelitian. Persiapan penelitian ini terbagi menjadi beberapa bagian, yaitu: observasi pengumpulan informasi daerah penelitian, dan perancangan kuesioner. Perancangan kuesioner melibatkan penentuan variabel variabel terpilih yang mempengaruhi nilai WTP. Setelah perancangan kuesioner ditentukannya jumlah responden menggunakan rumus slovin dengan tingkat error $10 \%$. Tingkat error yang digunakan $10 \%$ dikarenakan pertimbangan tingkat kesalahan yang terjadi saat pemilihan responden secara acak (Budiwaskito, 2010). Rumus slovin mentolelir maksimal kesalahan adalah 10\%. Semakin kecil kesalahan semakin akurat data yang didapat (Sugiyono, 2016)

\section{Pengumpulan Data}

Pengumpulan data dibagi menjadi 2 jenis yaitu data primer dan data sekunder.

Data primer, adalah data yang diperoleh atau dikumpulkan sendiri secara langsung berdasarkan observasi yang dilakukan pada area wisata GTJ. Data primer yang digunakan pada penelitian ini antara lain adalah data sosial ekonomi pengunjung,kondisi kelayakan fasilitas persampahan menurut pengunjung, kenyamanan pengunjung, dan kesediaan membayar pengunjung untuk pengembangan aspek lingkungan terpilih yaitu sistem pewadahan dan pengumpulan sampah.

Data sekunder, data yang diperoleh atau dikumpulkan dan disatukan oleh studi-studi sebelumnya atau yang diterbitkan oleh berbagai instansi lain. Data sekunder diperoleh dari instansi terkait yaitu pihak pengelola area wisata 
GTJ. Data yang digunakan yaitu jumlah kunjungan pertahun dari 5 tahun terakhir di area wisata GTJ. Data sekunder pada penelitian ini didapatkan dari PJT II bagian pariwisata selaku pengelola area wisata GTJ.

\section{Pengolahan dan Analisis Data}

Penelitian ini menggunakan beberapa metode analisis. Analisis deskriptif merupakan analisis karakteristik-karakteristik sosial ekonomi yang perlu dimasukan ke dalam hasil survei karena dianggap akan membantu untuk menerjemahkan respon terhadap pertanyaan valuasi (Muharram, 2015). Variabel-variabel yang digunakan dalam penelitian ini antara lain adalah: Umur, Jenis Kelamin, Jumlah Kunjungan per tahun, Lama Waktu yang Dihabiskan, Status, Jumlah Tanggungan Keluarga, Total Pendapatan, Keberadaan Sampah di Sekitar, Kenyamanan akan Sistem Pewadahan dan Pengumpulan.

Pengembangan pengelolaan sistem persampahan khususnya sistem pewadahan dan pengumpulan dilakukan untuk mengatasi pencemaran yang terjadi di area wisata GTJ. Perlunya pengantian dan penambahan wadah sampah serta perbaikan Tempat Pengumpulan Sampah Sementara (TPS) agar sesuai dengan SNI 19-2454-2002. Biaya yang dibutuhkan untuk pengembangan pengelolaan sistem persampahan tersebut didapat dari WTP yang dihasilkan dari valuasi ekonomi menggunakan prinsip CVM. Metode CVM melibatkan masyarakat dalam analisisnya, dalam hal ini pengunjung tempat wisata (Yustiani, Emilia \& Permana, 2017), (Hasbiah, Rochaeni \& Sutopo, 2018). Prinsip CVM yang digunakan adalah pasar hipotesa, metode penawaran, dan perhitungan rataan WTP.

Pasar hipotesa dibutuhkan untuk memberikan informasi terhadap responden tentang pengembangan pengelolaan sistem persampahan yang dilakukan dari kondisi eksisting hingga kondisi yang diharapkan.

Metode penawaran digunakan untuk melibatkan pengunjung dalam pengembangan pengelolaan sistem persampahan di area wisata GTJ berdasarkan WTP maksimum yang dikeluarkan (Fauzi, 2004). Metode penawaran terpilih adalah Payment Cards. Payment Cards digunakan dengan cara memberikan pilihan WTP responden terhadap fasilitas yang didapatkan.

\section{Hasil dan Pembahasan}

Penentuan Responden dan Jumlah Kunjungan

Penentuan responden pada penelitian ini merupakan pengunjung area wisata GTJ yang sesuai dengan hasil penentuan kriteria. Jumlah responden dihitung menggunakan rumus slovin dengan tingkat kesalahan $10 \%$ dari rata rata jumlah kunjungan area wisata GTJ selama lima tahun yaitu 219.611 seperti berikut :

$$
\begin{aligned}
& \mathrm{n}(10 \%) \quad=\frac{\mathrm{N}}{1+\mathrm{N}(\mathrm{e}) 2}=\frac{219.611}{1+219.611 \times(0.1)^{2}}= \\
& 99,9995 \approx 100 \text { orang }
\end{aligned}
$$

\section{Analisis Deskriptif}

Analisis deskriptif adalah suatu bentuk analisis dalam penelitian untuk melihat karakteristik individu dan menyimpulkannya berdasarkan sampel. Karakteristik tersebut meliputi sosial ekonomi yang dibutuhkan pada hasil akhir survei untuk membantu menerjemahkan dari setiap responden (Sugiyono, 2016).

Pengunjung area wisata GTJ menurut umur lebih banyak dikunjungi oleh responden dengan rentang umur 21 sampai 40 tahun dikarenakan pada usia tersebut pengunjung lebih sering berwisata dibandingkan umur 41 sampai 100 tahun. Terlihat persentase yang jauh terpaut antara umur 21 sampai 40 tahun (90\%) dan 41 sampai 100 tahun (10\%). Pengunjung dari umur 13 sampai 20 tahun tidak ada dikarenakan rata rata pengunjung dengan umur dibawah 20 tahun sudah bersama keluarga yang telah terwakilkan oleh responden umur 21 sampai 40 tahun dan 41 sampai 100 tahun. Grafik persentase pengunjung menurut umur dapat dilihat pada Gambar 1. 


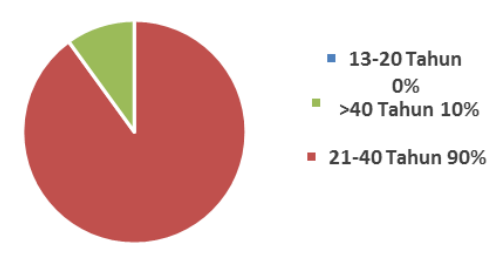

Gambar 1. Responden Area Wisata GTJ Berdasarkan Umur

Responden yang dibutuhkan merupakan responden yang memiliki tanggung jawab terhadap rekan atau keluarga yang dibawanya. Penanggung jawab tersebut diyakini mengetahui segala pengeluaran yang ditanggung jawabannya, menyebabkan jumlah laki laki (93\%) lebih banyak dari perempuan (7\%). Grafik persentase pengunjung berdasarkan jenis kelamin dapat dilihat pada Gambar 2.

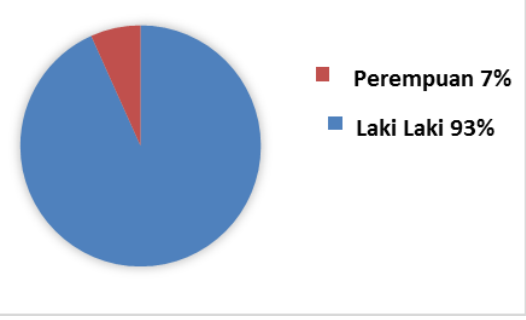

Gambar 2. Persentase Responden Area Wisata GTJ Berdasarkan Jenis Kelamin

Area wisata GTJ menarik minat wisatawan baru dan tetap membuat nyaman wisatawan yang telah berkunjung berkali kali sesuai dengan hipotesa awal yaitu pengunjung akan kembali berkunjung jika area wisata dapat membuat nyaman saat berkunjung.

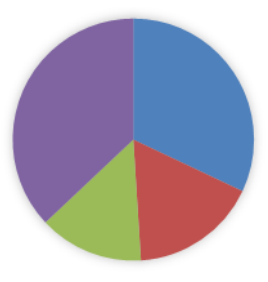

2 Kali $17 \%$

- 3 Kali $14 \%$

$>3$ Kali 37\%

Gambar 3. Persentase Responden Area Wisata GTJ Berdasarkan Jumlah Kunjungan
Grafik pengunjung berdasarkan jumlah kunjungan dapat dilihat pada Gambar 3.

Area wisata GTJ memiliki begitu banyak fasilitas yang dapat digunakan oleh pengunjung, sehingga pengunjung nyaman menghabiskan waktu di lokasi dengan waktu ideal yang dihabiskan sekitar 4 sampai 6 jam, sedangkan selain rentang jam tersebut jumlahnya jauh lebih sedikit. Rentang waktu 4 sampai 6 jam menjadi yang terbanyak dibandingkan yang lain dikarenakan 4 sampai 6 jam merupakan waktu yang cukup untuk menikmati seluruh fasilitas yang disediakan pengelola area wisata GTJ. Grafik persentase pengunjung berdasarkan lama waktu yang dihabiskan disajikan pada Gambar 4.

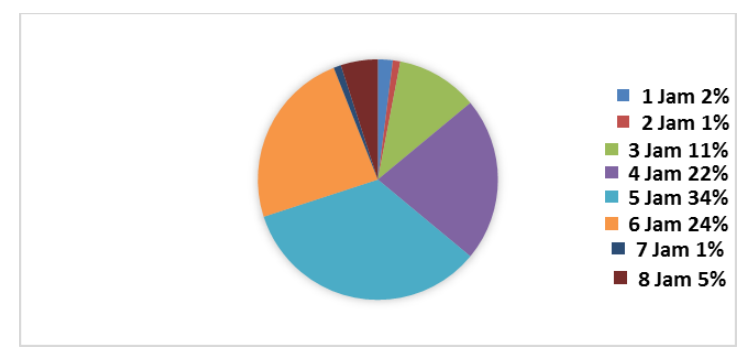

Gambar 4. Persentase Responden Area Wisata GTJ Berdasarkan Lama Waktu Yang Dihabiskan

Pengunjung area wisata GTJ sebagian besar sudah menikah ditunjukan besarnya persentase pengunjung yang sudah menikah yaitu $57 \%$. Area wisata GTJ merupakan tempat wisata dengan lebih banyaknya fasilitas yang dapat dinikmati oleh keluarga. Grafik persentase pengunjung area wisata GTJ berdasarkan status pernikahan disajikan pada Gambar 5.

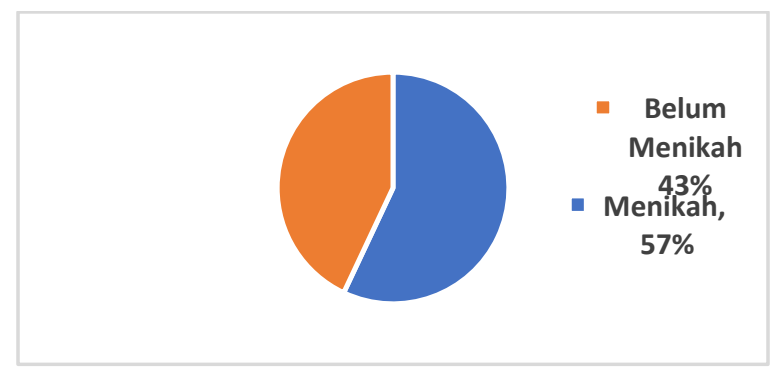

Gambar 5. Persentase Responden Area Wisata GTJ Berdasarkan Status Pernikahan 
Variabel jumlah tanggungan keluarga persentase tertinggi adalah responden yang tidak memiliki tanggungan keluarga (43\%). Semakin banyaknya jumlah tanggungan keluarga semakin jarang responden untuk berwisata.Gambar 6 menyajikan persentase pengunjung area wisata GTJ berdasarkan Jumlah Tanggungan Keluarga.

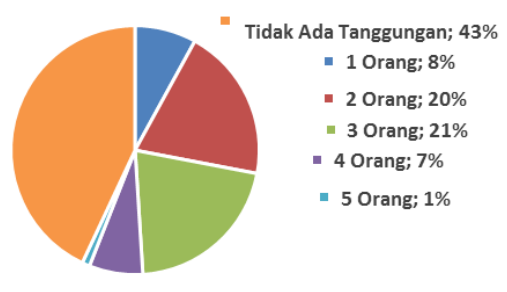

Gambar 6. Persentase Responden Area Wisata GTJ Berdasarkan Jumlah Tanggungan Keluarga

Responden yang memiliki pendapatan diatas Upah Minimum Regional (UMR) yaitu >Rp.3.300.000 lebih tinggi (86\%) dibandingkan yang lain (9\%, dan 5\%). Semakin tinggi total pendapatan semakin besar minat untuk berwisata. Grafik persentase pengunjung berdasarkan total pendapatan disajikan pada Gambar 7.

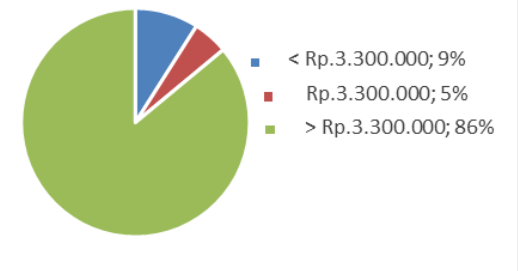

Gambar 7. Persentase Responden Area Wisata GTJ Berdasarkan Total Pendapatan

Semakin cepat perjalanan menuju area wisata dapat dikunjungi semakin sering pengunjung untuk mendatangi area wisata tersebut. Hipotesa tersebut dibuktikan dengan tingginya persentase pengunjung dengan waktu tempuh 0 menit sampai 60 menit yaitu $65 \%$ dibandingkan pengunjung dengan waktu tempuh lebih dari 60 menit. Grafik persentase pengunjung berdasarkan waktu tempuh disajikan pada Gambar 8.

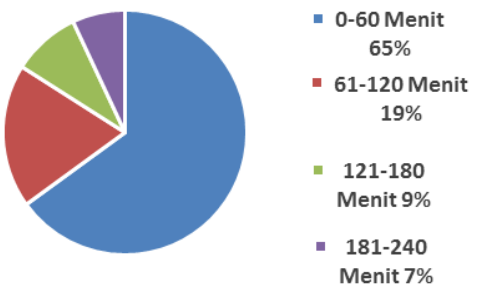

Gambar 8. Persentase Responden Area Wisata GTJ Berdasarkan Waktu Tempuh

Responden yang tidak menyediakan biaya khusus untuk berwisata lebih banyak dibandingkan yang telah menyediakan biaya khusus untuk berwisata dikarenakan biaya berwisata di area wisata GTJ terjangkau sehingga tanpa menyediakan biaya khusus dapat tetap berwisata ke area wisata GTJ. Gambar 9 menyajikan persentase pengunjung area wisata GTJ berdasarkan penyediaan biaya untuk berwisata.

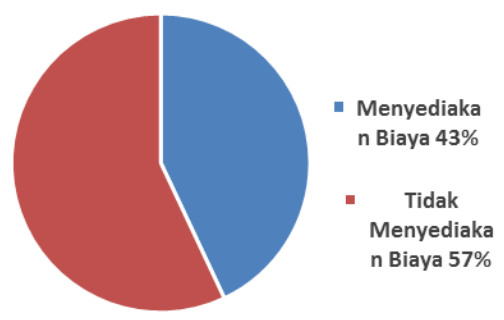

Gambar 9. Persentase Responden Area Wisata GTJ Berdasarkan Penyediaan Biaya Untuk Berwisata.

Keberadaan sampah di sekitar mengganggu pengunjung, untuk memastikan apakah pengunjung memperhatikan keberadaan sampah disekitar diperlukannya kuesioner tersebut. $100 \%$ pengunjung mengatakan ya terhadap keberadaan sampah di sekitar. Kesimpulan dari data tersebut bahwa banyaknya sampah yang tidak berada pada wadah sampah yang mencemari area sekitar pengunjung. Grafik 
persentase pengunjung melihat keberadaan sampah di sekitar disajikan pada Gambar 10.

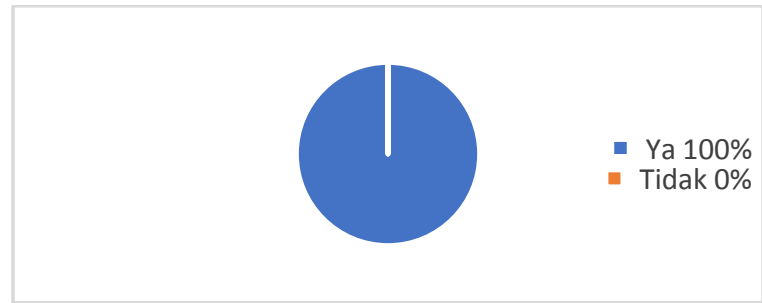

Gambar 10. Persentase Responden Melihat Keberadaan Sampah di Sekitar.

Keberadaan sampah di sekitar menunjukkan kurang baiknya sistem pewadahan dan pengumpulan sampah di area wisata GTJ. Persepsi pengunjung dibutuhkan untuk mengetahui kenyamanan yang didapat dengan sistem pewadahan dan pengumpulan yang ada di area wisata GTJ. Pengunjung $21 \%$ mengatakan cukup, 59\% mengatakan kurang, dan 20\% mengatakan tidak nyaman terhadap sistem pewadahan dan pengumpulan sampah di area wisata GTJ. Persentase kenyamanan responden terhadap sistem pewadahan dan pengumpulan di area wisata GTJ disajikan pada Gambar 11.
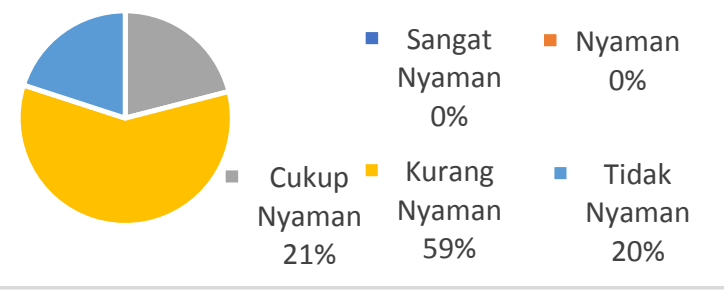

Gambar 11. Persentase Responden Terhadap Kenyamanan Akan Sistem Pewadahan dan Pengumpulan di Area Wisata GTJ

Pengembangan Pengelolaan Sistem Persampahan Khususnya Sistem Pewadahan dan Pengumpulan Sampah

\section{Pasar Hipotesa}

Pengunjung area wisata GTJ diberikan pasar hipotesa. Perbandingan antara kondisi eksisting dan kondisi yang sesuai dengan SNI 19-24542002 disajikan pada pasa hipotesa. Kondisi eksisting wadah sampah terlihat bahwa tidak adanya perbedaan warna antara wadah sampah organik maupun anorganik dengan kondisi yang sudah mulai rusak. Kondisi harapan wadah sampah memiliki perbedaan warna berdasarkan jenis sampah dan memiliki kondisi yang sangat baik. Perbandingan tersebut disajikan pada Gambar 12 dan Gambar 13.

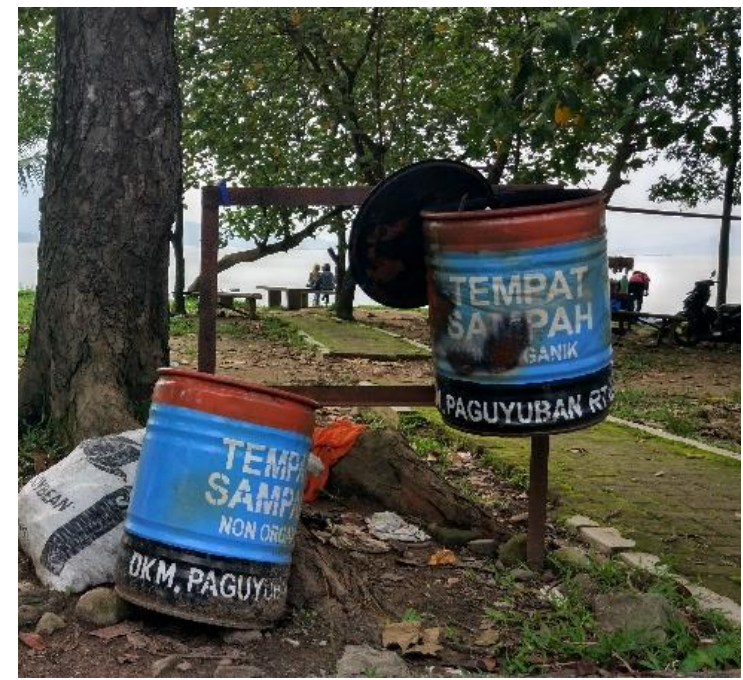

Gambar 12. Kondisi Eksisting Wadah Sampah

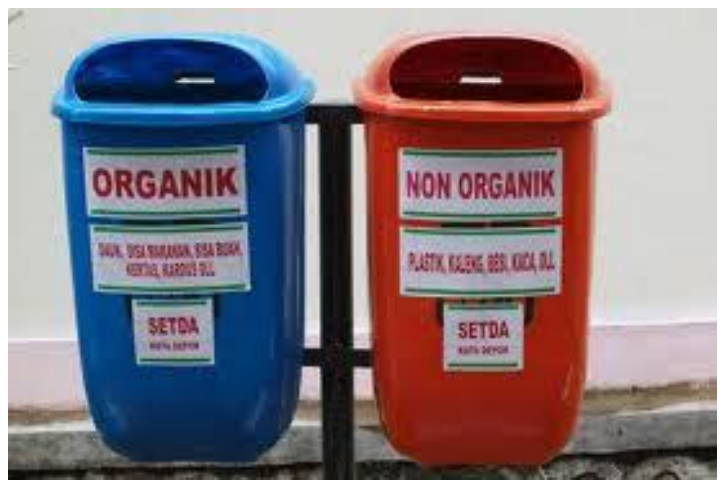

Gambar 13. Kondisi Wadah Sampah Sesuai Standar SNI 19-2454-2002

Tidak adanya petugas kebersihan di area berkumpul membuat sampah dibuang tidak pada tempatnya oleh pengunjung. Terlihat pada Gambar 14 kondisi eksisting memiliki banyak sampah yang tercecer sedangkan Gambar 15 memperlihatkan kondisi harapan memiliki kebersihan sehingga tidak ada sampah tercecer. 


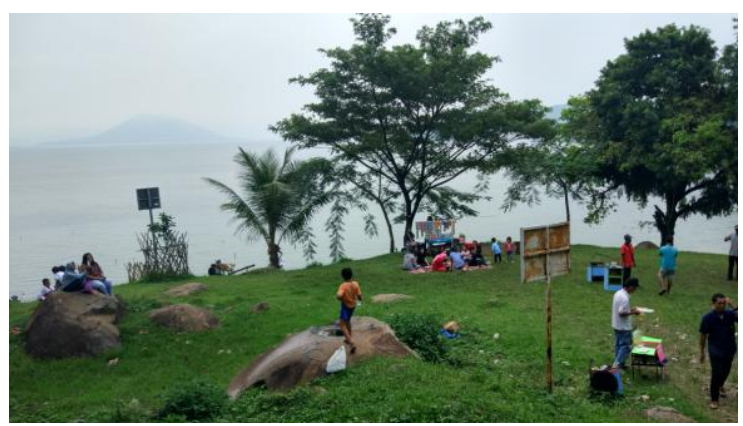

Gambar 14. Tidak adanya Petugas Kebersihan

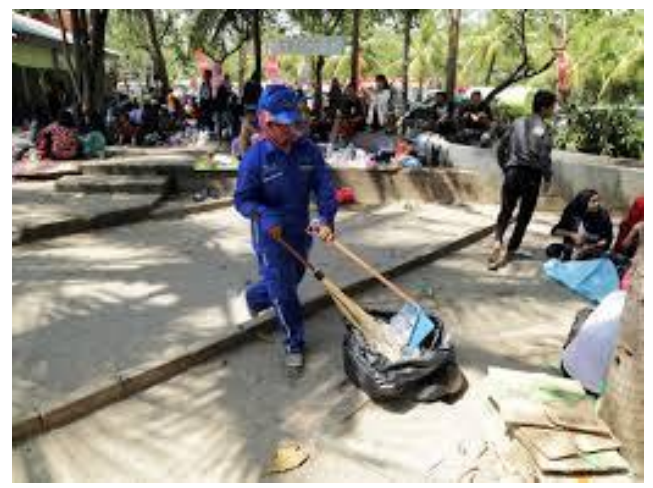

Gambar 15. Adanya Petugas Kebersihan

TPS yang terbuka dapat menimbulkan penyebaran vektor penyakit. Bak pengumpul yang dibiarkan terbuka seperti pada kondisi eksisting di Gambar 16 menyebabkan air dan hewan dengan mudah masuk dan dapat menyebarkan penyakit serta membuat sampah tercecer di sekitar bak kumpul. Kondisi harapan seperti pada Gambar 17 memiliki penutup sehingga air dan hewan tidak bisa masuk dan menjadi vektor penyakit.

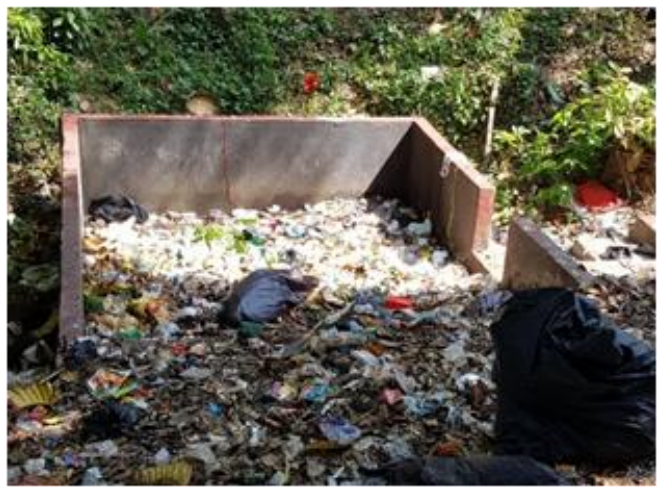

Gambar 16. Kondisi Eksisting Tempat Pengumpulan Sementara

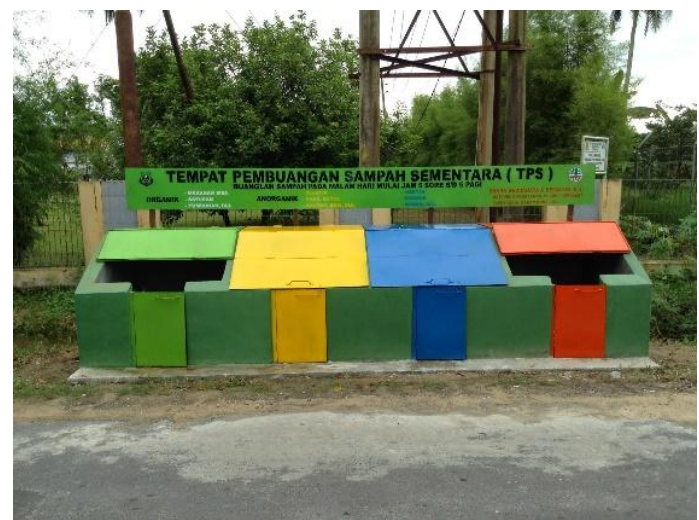

Gambar 17. Kondisi Harapan Tempat

Pengumpulan Sementara Sesuai SNI 19-24542002

\section{Metode Penawaran}

Metode penawaran yang digunakan adalah Payment Card. Pengunjung memilih membayar berdasarkan fasilitas yang akan didapatkan.

Pengunjung dengan menambah HTM kurang dari Rp.5.000 mendapatkan penggantian wadah sampah dan adanya petugas sampah di area kumpul pengunjung.

Pengunjung dengan menambah HTM Rp.5.000 mendapatkan penggantian wadah sampah, adanya petugas sampah di area kumpul pengunjung, dan perbaikan Tempat Pengumpulan Sampah Sementara (TPS)

Pengunjung dengan menambah HTM Rp.7.000 mendapatkan penggantian dan penambahan wadah sampah, adanya petugas sampah di tempat berkumpul, dan perbaikan TPS.

Pengunjung dengan menambah HTM lebih besar dari Rp.7.000 mendapatkan penggantian dan penambahan wadah sampah, adanya petugas sampah di tempat berkumpul, dan perbaikan TPS. Pembeda dari penambahan HTM Rp.7.000 adalah jumlah petugas sampah yang lebih banyak.

\section{Willingnes to Pay}

Pengembangan aspek lingkungan khususnya sistem pewadahan dan pengumpulan membutuhkan biaya yang berasal dari kesediaan membayar pengunjung area wisata GTJ. WTP 
rata-rata pengunjung area wisata GTJ adalah Rp.4.500 dengan total WTP adalah Rp.988.330.500,-.

\section{Kesimpulan}

Hasil yang diperoleh dari valuasi nilai ekonomi area wisata GTJ menggunakan prinsip CVM adalah nilai WTP rata-rata adalah Rp.4.500,/pengunjung, nilai WTP total adalah Rp.988.330.500. Aspek lingkungan terpilih yang dikembangkan adalah sistem pewadahan dan pengumpulan sampah sesuai dengan hasil kuesioner terhadap pengunjung yang membutuhkan perbaikan pada kedua sistem tersebut. Hasil dari metode penawaran yang dipilih adalah penambahan HTM kurang dari Rp.5.000.

\section{Daftar Pusataka}

Budiwaskito, R. (2010). Margin Of Error Probabilitas dan Statistik. Bandung: Institut Teknologi Bandung

Fauzi, A. (2004). Ekonomi Sumber Daya Alam dan Lingkungan: Gramedia Pustaka Utama.

Hasbiah, A.W., Rochaeni, A., Sutopo, A.F. (2018). Analisis Kesediaan Membayar (Willingness to Pay) dan Kesediaan untuk Menerima Kompensasi (Willingnes to Accept) dari Keberadaan tempat Penampungan Sementara
Ciwastra dengan Contingent Valuation Method. Infomatek: Jurnal Informatika, Manajemen dan Teknologi, 20(2), 107116.

Marpaung. (2002). Pengetahuan Kepariwisataan. Bandung: Alfabeta.

Muharram, R. (2015). Willingness to Pay Pengguna Angkutan Umum untuk Pelayanan Bus Rapid Transit (BRT) Koridor I di Kota Surakarta: Aplikasi Metode Contingent Valuation. Universitas Sebelas Maret.

Sugiyanto, C., \& Fikri, A. A. H. S. F. (2016). Ekonomi Sumber Daya Alam (1 ed.). Yogyakarta: UPP STIM YKPN.

Sugiyono. (2016). Metode Penelitian Kuantitatif Kualitatif dan $R \& D$. Bandung: Alfabeta.

UU Nomor 10 Tahun 2009. (2009). Undang Undang Nomor 10 Tentang Kepariwisataan. Jakarta: Sekretariat Negara.

Yustiani, Y.M., Emilia, Permana, A. (2017). Kajian Valuasi Ekonomi Wana Wisata Taman Hutan Berdasarkan Pendapat Masyarakat Pengunjung (Studi Kasus Taman Hutan Tangkuban Perahu). Journal of Community Based Environmental Engineering and Management, 1(1), 1-9. 